\title{
PENGARUH KOMPETENSI DAN MOTIVASI TERHADAP KINERJA KARYAWAN DENGAN KEPUASAN KERJA SEBAGAI VARIABEL MODERASI DI PATRA SEMARANG CONVENTION HOTEL
}

\author{
Rezki Alhamdi \\ Program Studi Manajemen Kuliner Politeknik Pariwisata Batam \\ Jl. Gajah Mada, Vitka City Complex, Tiban Ayu, Sekupang Batam
}

Korespondensi dengan penulis

Rezki Alhamdi: Telp: 085361833769

Email: Rezki.alhamdii@gmail.com

\begin{abstract}
This research was conducted to find out the influence of competence and motivation on employee performance and working satisfaction as moderation variable. This research used primary data which was questionnaire. The sample used in this research was 60 respondents. This research was expected to provide useful information for leaders and employees. The obtained data were processed using descriptive analysis and quantitative statistical analysis. Quantitative analysis applied multiple regression analysis to find the independent variable towards the dependent one. This result of the research showed that both competence and motivation influenced the employee performance and working satisfaction as moderation variable in Patra Semarang Convention Hotel.

Keywords: competence, motivation, working satisfaction, and employee performance.
\end{abstract}

\begin{abstract}
Abstrak
Penelitian ini dilakukan untuk mengetahui pengaruh kompetensi dan motivasi terhadap kinerja karyawan dan kepuasan kerja sebagai variabel moderasi. Penelitian ini menggunakan data primer yaitu kuesioner. Sampel yang digunakan dalam penelitian ini adalah 60 responden. Penelitian ini diharapkan dapat memberikan informasi yang berguna bagi para pemimpin dan karyawan. Data yang diperoleh diolah menggunakan analisis deskriptif dan analisis statistik kuantitatif. Analisis kuantitatif menggunakan analisis regresi berganda untuk menemukan variabel independen terhadap variabel dependen. Hasil penelitian menunjukkan bahwa baik kompetensi dan motivasi mempengaruhi kinerja karyawan dan kepuasan kerja sebagai variabel moderasi di Hotel Konvensi Patra Semarang. Kata kunci: kompetensi, motivasi, kepuasan kerja, dan kinerja karyawan.
\end{abstract}

Kata kunci: kompetensi, motivasi, kepuasan kerja, kinerja karyawan

\section{PENDAHULUAN}

Pariwisata saat ini mendapat perhatian yang serius oleh pemerintah hal ini terbukti dengan banyaknya APBN yang di anggarkan pemerintah untuk memperbaiki fasilitas, mempromosikan, menghapus atau memperbaiki regulasi yang dapat menghambat pertumbuhan pariwisata. Pariwisata merupakan sektor 
bisnis yang tidak membutuhkan banyak modal atau biaya untuk membangunnya, berbeda dengan sektor tambang ataupun sektor yang bergerak di bidang lain. Indonesia telah mempunyai alam, budaya, dan keramah tamahan penduduknya yang menjadikan modal dasar untuk membangun objek wisata yang dapat menggerakkan perkonomian. Suatu wilayah yang memiliki objek wisata di suatu tempat, maka akan banyak pengunjung atau wisatawan yang ingin datang berkunjung untuk menikmati objek tersebut.

Ada banyak defenisi yang menjelaskan tentang pariwisata, salah satunya adalah seseorang atau kelompok orang yang melakukan suatu perjalanan wisata yang disebut dengan wisatawan (Suwantoro, 2004:4). Ketika suatu objek wisata didatangi oleh banyak wisatawan yang berkunjung, maka wisatawan mempunyai kebutuhan di saat mereka melakukan perjalanan wisata.

Sebagai upaya dalam memenuhi kebutuhan wisatawan maka sarana pokok yang harus dipenuhi untuk menunjang pariwisata yaitu tour operator, tourist transportation, hotel, motel, resort, restoran, tourist attractions, souvenir shop dan money changers (Yoeti, 2010:141). Selain fasilitas penunjang seperti restoran dan pemandu wisata, yang tidak kalah penting adalah akomodasi. Salah satu jenis akomodasi favorit para wisatawan adalah hotel.

Di era sekarang, hotel bukanlah sesuatu hal yang mewah karena semua orang dapat menginap di hotel karena banyak jenis hotel mulai yang full service ataupun hotel budget, mulai yang mempunyai fasilitas kolam renang hingga hotel yang hanya mempunyai tempat tidur saja. Tamu dapat memilih hotel sesuai dengan kebutuhan. Dewasa ini pemesanan hotel tidak harus melalui telepon atau datang langsung ke hotel. Beberapa tahun belakangan ini banyak aplikasi ponsel pintar ataupun situs internet yang menyediakan layanan pemesanan kamar hotel. Hal tersebut merupakan bentuk kemajuan teknologi sehingga memudahkan calon tamu untuk memilih hotel sesuai dengan kebutuhan tanpa harus datang dan bertanya kepada resepsionis tiap hotel, untuk menanyakan bagaimana hotelnya dan berapa harganya. Kemajuan teknologi membuat pihak hotel harus bekerja lebih baik dan harus berkompetisi dengan hotel yang lain dalam hal mendapatkan tamu. 
Kota Semarang mempunyai hotel yang cukup banyak jumlahnya. Sehingga untuk mendapatkan tamu ada beberapa cara hotel untuk menarik calon tamu untuk menginap mulai memberikan diskon, memberikan fasilitas lebih atau juga menjaga kualitas pelayanan hotel agar tamu yang datang akan menjadi pelanggan setia yang akan kembali lagi untuk menginap karena puas dengan pelayanan hotel yang telah di berikan. Agar pelayanan hotel dapat di tingkatkan maka dibutuhkan beberapa sumber daya manusia dengan unsur untuk menunjangnya di antaranya adalah kompetensi, motivasi dan lingkungan kerja untuk mendapatkan kinerja yang baik. Kinerja itu merupakan hasil dari sebuah pekerjaan hal tersebut sesuai dengan pernyataan dari Charles (1985:105) menjelaskan "Performance may be defined as the extent to which behavior results in attainment of work goals", yang dapat di artikan kinerja dapat didefinisikan sebagai sejauh mana perilaku hasil dalam pencapaian tujuan kerja di perusahaan ataupun di organisasi. Pernyataan di atas dapat di dikembangkan lagi yaitu untuk mendapatkan hasil yang bagus untuk perusahaan dibutuhkan pencapaian.

Kompetensi merupakan tingkat kemampuan pekerja untuk dapat menyelesaikan tugas-tugasnya. pernyataan ini diungkapkan oleh Amstrong (1994) dalam Dharma (2009:141) menjelaskan bahwa kompetensi adalah dimensi perilaku dari sebuah peran perilaku yang di perlukan seseorang untuk melaksanakan pekerjaan secara memuaskan dengan adanya kompetensi yang baik maka tanggung jawab- tanggung jawab ini dapat di selesaikan. Ada beberapa cara untuk mengukur kompetensi seseorang itu mulai dari hasil pekerjaan, pendidikan terakhir atau dari pengalaman kerja. Sejak beberapa tahun yang lalu pemerintah mulai memperhatikan karyawan khususnya karyawan hotel dalam hal pengakuan dengan cara pemberian sertifikat kompetensi. Berdasarkan SKKNI atau standar kompetensi kerja nasional ada beberapa yang mencakup pada individu dapat dikatakan berkompetensi yaitu pengetahuan, keterampilan dan sikap kerja. Sertifikat ini di berikan kepada karyawan yang mempunyai kemampuan dalam kompetensi tertentu yang telah melakukan serangkaian ujian dan penilaian terhadap kemampuannya. 
Selanjutnya yang dapat mempengaruhi kualitas pelayanan adalah motivasi. Motivasi merupakan keinginan seseorang melakukan sesuatu. Motivasi berasal dari keinginan karyawan untuk melakukan atau tidak melakukan sesuatu. menurut Kamus Besar Bahasa Indonesia (KBBI) motivasi adalah dorongan yang timbul pada diri seseorang sadar atau tidak sadar untuk melakukan tindakan dengan tujuan tertentu, atau usaha-usaha yang dapat menyebabkan seseorang atau sekelompok orang tertentu bergerak melakukan sesuatu karena ingin mencapai tujuan yang dikehendakinya atau mendapat kepuasan atas perbuatannya. Ada beberapa faktor mulai gaji, manajemen yang baik dan banyak hal yang lain. Untuk itu manajemen hotel harus berupaya sekuat tenaga agar membuat motivasi kerja meningkat.

Kepuasan kerja merupakan salah satu hal yang terpenting di dalam melakukan aktivitas pekerjaan kepuasan kerja mengacu pada sikap umum karyawan sikap umum karyawan terhadap pekerjaannya hal ini di jelaskan juga oleh Robbins (2007:53) yang menjelaskan bahwa kepuasan kerja mengacu pada sikap umum karyawan sikap umum karyawan terhadap pekerjaannya. Sehingga dari keterangan di atas dapat disimpulkan bahwa kepuasan kerja dapat meningkatkan kinerja karyawan.

\section{METODE}

Penelitian ini menggunakan metode kuantitatif. Lokasi penelitian ini dilakukan di Patra Semarang Convention Hotel jalan Sisingamangaraja, Candi Baru, Semarang, Jawa Tengah.

Adapun waktu yang peneliti gunakan untuk melakukan penelitian ini dari bulan juli hingga november 2016. Peneliti melakukan penelitian dengan menggunakan kuisioner dengan mengambil sample terhadap populasi. Adapun metode pengambilan sample dengan menggunakan metode slovin. Adapun Populasi yang digunakan untuk penelitian ini adalah seluruh karyawan yang berjumlah 127 karyawan Patra Jasa Semarang , Jawa Tengah. dengan rumus berikut ini:

$$
\mathrm{n}=\frac{\mathrm{N}}{1+\mathrm{N}(\mathrm{e})^{2}}
$$




\section{Keterangan:}

$\mathrm{N}=$ = Ukuran sampel yang dibutuhkan

$\mathrm{N} \quad=$ Ukuran Populasinya

e $\quad=$ Nilai Kritis/Margin Error yang

diperkenankan (batas ketelitian 5-10 persen atau sampai 0,2)

$$
\begin{gathered}
\mathrm{n}=\frac{127}{1+127(0,1)^{2}} \\
\mathrm{n}=\frac{127}{2,27} \\
\mathrm{n}=55,9
\end{gathered}
$$

Penelitian ini akan melibatkan 60 sampel (pembulatan 55,9) dari populasi karyawan di Patra Semarang Convention Hotel.

\section{HASIL DAN PEMBAHASAN}

\section{Pengaruh Kompetensi Terhadap Kinerja Karyawan}

Penelitian yang di lakukan oleh peneliti ditemukan bahwa bahwa Kompetensi berpengaruh positif dan signifikan terhadap kinerja karyawan. Hal ini terlihat pada seseorang harus mempunyai kompetensi yang sesuai dengan pekerjaan yang akan ia selesaikan di departemen tempat ia bekerja hal tersebut di perkuat dengan pernyataan dari Spencer (1993) yang menyatakan bahwa kompetensi adalah suatu karakteristik dari suatu individu yang di hubungkan dengan hasil yang diperoleh dalam suatu pekerjaan. Di tambah lagi saat ini pemerintah selaku pemberi sertifikasi dan penyelenggara melakukan sertifikasi yang di lakukan sekali setahun untuk memberikan sertifikat secara gratis. Hal itu membuktikan bahwa kompetensi sangat di perlukan untuk menyelesaikan pekerjaan yang ada di hotel. Tentu saja untuk mendapatkan sertifikat yang di akui oleh nasional ini mereka para pelaku pariwisata khususnya perhotelan harus memiliki kompetensi sesuai bidang yang ia tekuni.

Kompetensi yang merupakan bentuk kemampuan karyawan hotel dalam menyelesaikan pekerjaannya baik tingkat kesulitan yang mudah hingga yang tersulit. Di hotel sendiri yang mempunyai beberapa departemen seperti front office, food and berevage dan house keeping setiap karyawan mempunyai kompetensi yang 
berbeda-beda sebagai contoh seorang juru masak di dapur mereka harus mempunyai kompetensi yang dapat menunjang tugasnya yaitu memasak makanan untuk tamu yang menginap dengan rasa, tampilan, kebersihan, kualias makanan harus yang terbaik

Adapun indikator dari kompetensi adalah bekerja sesuai dengan kebutuhan perusahaan. Hal ini terlihat bagaimana karyawan mendahulukan prioritas dalam hal melakukan pekerjaannya. Patra Semarang Convention Hotel merupakan salah satu hotel yang mempunyai convention di kota Semarang oleh sebab itu hotel ini cukup sibuk apa bila ada acara yang mengisi ruang convention mereka karena harus menyiapkan segala kebutuhan, di sini peran menejer sangat penting untuk melihat mana yang menjadi prioritas dan tentu tidak meninggalkan tanggung jawab yang lain.

Saat ini banyaknya sekolah, perguruan tinggi, akademi dan lembaga pelatihan yang mendidik dan melatih siswanya untuk dapat menguasai kompetensi perhotelan.

Hal itu membuktikan betapa pentingnya kompetensi untuk meningkatkan kinerja karyawan hotel khususnya di hotel Patra Semarang Convention Hotel. Menurut salah satu karyawan human resouses departemen (HRD) bahwa karyawan hotel ini 75\% karyawannya memiliki sertifikasi profesi yang di keluarkan oleh pemerintah dan juga karyawan hotel mempunyai latar belakang akademis yang sama atau sesuai dengan profesi yang di jalankan saat ini.

Patra Semarang Convention Hotel yang merupakan hotel kedua yang terbaik di dari Patra Jasa hotel yang tersebar di seluruh Indonesia adalah sebagai bukti bahwa kinerja baik berasal dari kompetensi yang baik pula.

\section{Pengaruh Motivasi Terhadap Kinerja Karyawan}

Pada Patra Semarang Convention hotel di temukan bahwa motivasi berpengaruh positif dan signifikan terhadap kinerja karyawan. Motivasi adalah salah satu "penggerak" karyawan untuk bekerja sungguh-sungguh dan menghasilkan kinerja yang baik untuk hotel dan pastinya untuk pelayanan yang terbaik untuk tamu yang menginap di hotel. Dengan motivasi yang di punyai 
seorang karyawan dapat membuat mereka bekerja dengan baik dan prima. Hal tersebut sama dengan yang di jelaskan pada Kamus Besar Bahasa Indonesia (KBBI) motivasi adalah" dorongan yang timbul pada diri sendiri seseorang sadar atau tidak sasar untuk melakukan tindakan dengan tujuan tertentu, atau usaha-usaha yang dapat menyebabkan seseorang atau sekelompok orang tertentu bergerak melakukan sesuatu karena ingin mencapai tujuan yang di kehendakinya atau mendapat kepuasan atas perbuatannya".

Tentu saja untuk mendapatkan motivasi yang baik seorang manajemen hotel harus memikirkan apa kebutuhan karyawan mereka, seperti yang kita ketahui bahwa salah satu yang motivasi bekerja adalah untuk memenuhi kebutuhan mereka. Dengan motivasi untuk memenuhi kebutuhan tersebut seseorang bekerja dengan baik dengan harapan mendapatkan gaji ataupun bayaran atas kerja keras yang telah mereka lakukan.

Karyawan Patra Semarang Convention Hotel mereka bekerja dengan baik untuk melayani tamu-tamu baik yang menginap ataupun yang melakukan kegiatan seperti menyelenggarakan acara dan lainnya. Dengan pelayanan yang baik tamu akan banyak menginap dan menggunakan jasa hotel. Seperti peraturan hotel-hotel lain di Indonesia bahwa setiap tamu yang menggunakan jasa di hotel akan di pembayaran mereka akan termasuk pajak dan service yang berjumlah $21 \%$ dari harga barang atau jasa yang di beli. Service yang di bayarkan oleh tamu sebanyak 11 persen tersebut akan di kumpulan dan di bagikan setiap bulannya sehingga karyawan akan mendapat tambahan penghasilan selain dari gaji pokok yang mereka terima.

\section{Pengaruh Kepuasaan Kerja Terhadap Kinerja Karyawan}

Kepuasan Kerja berpengaruh positif dan signifikan terhadap kinerja karyawan. Kinerja karyawan di tidak lepas dari kepuasan mereka dalam bekerja. Kepuasan itu jarang dibuktikan dengan sikap karyawan terhadap pekerjaan mereka, bagaimana mereka pandangan mereka terhadap hal yang di lakukan.

Kepuasan kerja muncul setelah adanya sikap menyukai pekerjaan yang menjadi rutinitas pekerja. Hal tersebut Sutrisno (2009: 74) bahwa kepuasan kerja 
sebagai suatu reaksi emosional ini merupakan akibat dari dorongan, keinginan atau tuntutan dan harapan, harapan karyawan terhadap pekerjaan yang di hubungkan dengan realitas-realitas yang di rasakan karyawan, sehingga menimbulkan suatu reaksi emosional yang berwujud perasaan senang, perasaan puas, ataupun perasaan tidak puas. Sebagai contoh seorang karyawan hotel apabila mereka mempunyai kepuasan kerja akan terlihat dari bagaimana karyawan itu bersikap, bekerja dan kedisiplinannya. Contoh yang jelas apabila karyawan tidak mempunyai kepuasan kerja makan mereka akan mereka berat dalam menjalankan tugas dan kurang disiplin dalam masuk kerja dan akan memperlama waktu istirahatnya bahwa sering mengeluh akan kegiatannya di tempat kerja. Sebaliknya bagi yang mempunyai kepuasan kerja mereka sering bekerja dengan hati riang dan bekerja dengan ikhlas tanpa di perintahkan oleh atasan dan akan membuat pekerjaan sebaik mungkin menurut mereka meski terkadang waktu istirahat dan waktu pulang kerja tertunda.

\section{Pengaruh Kompetensi Terhadap Kinerja Karyawan Dengan Kepuasaan Kerja Sebagai Variabel Moderasi}

Kompetensi berpengaruh positif dan signifikan terhadap kinerja karyawan dengan kepuasan kerja sebagai variabel moderasi. Kompetensi merupakan hal yang dibutuhkan seorang karyawan hotel untuk melaksanakan tugas dengan baik. Kompetensi biasa di dapatkan dalam berbagai hal mulai dari pendidikan, pelatihan dan juga pengalaman. Tanpa hal tersebut kegiatan pelayanan jasa di hotel tidak akan baik apabila tidak mempunyai kemampuan yang sesuai dengan profesinya yang di lakukannya, juru masak tidak akan bisa membuat makanan untuk tamu di restoran, pelayan restoran tidak mengerti bagaimana pelayanan yang baik dan petugas tata graha tidak bisa membersihkan kamar dengan benar dan waktu di tentukan. Oleh sebab itu kompetensi dibutuhkan di setiap kegiatan di hotel.

\section{Pengaruh Motivasi Terhadap Kinerja Dengan Kepuasan Kerja Sebagai Variabel Moderasi}

Motivasi berpengaruh positif terhadap kinerja karyawan dengan kepuasan kerja sebagai variabel moderasi. Motivasi merupakan alasan seseorang untuk 
melakukan sesuatu sama halnya dengan karyawan di hotel mereka bekerja dan melayani dengan tujuan serta motivasi yang berbeda. Untuk hal tersebut maka motivasi merupakan hal yang penting untuk perlu di perhatikan baik dari pihak manajemen hotel, menejer bahwakan karyawan itu sendiri.

Kepuasan kerja hal yang juga perlu di perhatikan dalam meningkatkan kinerja karyawan. Karyawan yang mempunyai kepuasan dalam bekerja akan cendrung bekerja dengan ikhlas tanpa menghitung-hitung apa yang telah ia lakukan untuk hotel. Mereka biasanya melakukan sesuatu tanpa di perlu menunggu perintah dari atas, apabila mereka merasa ada yang baik maka di kerjakan dan apa bila ada yang salah dalam hal pekerjaannya mereka akan segera memperbaiki kinerja mereka tersebut. Biasanya karyawan yang telah mempunyai kepuasan kerja identik dengan loyalitas dan displin dalam bekerja. Hal tersebut sesuai dengan pernyataan dari Fathoni (2006) yang mengatakan bahwa sikap kepuasan kerja tercermin oleh moral kerja, kedisiplinan dan prestasi kerja.

\section{Pengaruh Kompetensi dan Motivasi Terhadap Kinerja Karyawan Dengan Kepuasan Kerja Sebagai Variabel Moderasi}

Kompetensi dan motivasi berpengaruh positif dan signifikan terhadap kinerja karyawan dengan kepuasan kerja sebagai variabel moderasi. Keahlian dalam hal mengerjakan sesuatu atau yang sering kita sebut dengan istilah kompetensi. Kompetensi mencakup banyak hal mulai dari pengetahuan, kemampuan dan juga pengalaman sehingga pekerjaan tersebut dapat di kerjakan dengan sempurna. Karyawan hotel mulai dari front office, house keeping, kitchen hingga security mempunyai kompetensi sesuai dengan profesi mereka untuk memberikan pelayanan yang terbaik untuk tamu yang akan menginap khususnya di Patra Semarang Convention Hotel.

\section{Simpulan}

Berdasarkan hasil penelitian, analisis data dan pengujian hipotesis yang telah peneliti lakukan di Patra Semarang Convention Hotel, maka dapat di tarik kesimpulan sebagai berikut: 
1. Ada pengaruh positif dan signifikan antara Kompetensi terhadap Kinerja Karyawan di Patra Semarang Convention Hotel.

2. Ada pengaruh positif dan signifikan antara Motivasi terhadap Kinerja Karyawan di Patra Semarang Convention Hotel.

3. Ada pengaruh positif dan signifikan antara Kepuasan Kerja terhadap Kinerja Karyawan di Patra Semarang Convention Hotel.

4. Ada pengaruh positif dan signifikan antara Kompetensi terhadap Kinerja Karyawan dengan Kepuasaan Kerja sebagai variabel Modarasi di Patra Semarang Convention Hotel.

5. Ada pengaruh positif dan signifikan antara Motivasi terhadap Kinerja Karyawan dengan Kepuasaan Kerja sebagai variabel Moderasi di Patra Semarang Convention Hotel.

6. Kompetensi dan Motivasi secara bersama-sama berpengaruh positif dan signifikan terhadap Kinerja Karyawan dengan Kepuasaan Kerja sebagai variabel Moderasi di Patra Semarang Convention Hotel.

\section{KESIMPULAN}

Berdasarkan hasil penelitian yang telah dilakukan maka dapat disimpulkan sebagai berikut:

1. Berdasarkan hasil analisis regresi, koefisien regresi variabel perceived usefulness memiliki tanda positif yaitu 0,427 sehingga variabel perceived usefulness mempunyai pengaruh yang positif terhadap perilaku wisatawan. Koefisien regresi variabel ease of use memiliki tanda positif sebesar 0,534 yang mengandung implikasi bahwa ease of use mempunyai pengaruh yang positif terhadap perilaku wisatawan.

2. Dalam penelitian ini variabel perceived usefulness dan ease of use berpengaruh secara signifikan terhadap perilaku wisatawan sebesar 77,6\%. Hal ini menunjukkan bahwa wisatawan memanfaatkan aplikasi perjalanan karena selain mudah dipahami juga mudah untuk dipelajari. 
3. Berdasarkan uji F, model regresi dapat dinyatakan bahwa secara simultan variabel perceived usefulness dan ease of use berpengaruh terhadap perilaku wisatawan.

4. Hasil uji $\mathrm{t}$ menunjukkan bahwa secara parsial variabel perceived usefulness berpengaruh signifikan terhadap perilaku wisatawan. Nilai signifikan dari variabel ease of use yang $<0,05$, maka dapat dinyatakan secara parsial ease of use berpengaruh signifikan terhadap perilaku wisatawan.

5. Hasil analisa korelasi antar variabel perceived usefulness memiliki nilai korelasi yang kuat terhadap variabel perilaku wisatawan, yaitu sebesar 0,792. Sedangkan korelasi antar variabel ease of use memiliki nilai korelasi terhadap variabel perilaku wisatawan sebesar 0,831 . Hal ini menunjukkan bahwa variabel ease of use memiliki korelasi yang lebih kuat terhadap variabel perilaku wisatawan dibandingkan dengan variabel perceived usefulness terhadap variabel perilaku wisatawan.

Beberapa saran yang dapat dipertimbangkan untuk penelitian yang akan datang antara lain memperluas cakupan sampel untuk meningkatkan generalisasi hasil penelitian, menambah variabel dari Technology Acceptance Model (TAM) antara lain variabel self-identity dan perceived enjoyment dan memperbanyak kembali referensi penelitian sebagai dasar pemahaman.

\section{DAFTAR RUJUKAN}

Asosiasi Penyelenggara Jasa Internet Indonesia (2016). Infografis Penetrasi \& Perilaku Pengguna Internet Indonesia. https://apjii.or.id/downfile/file/surveipenetrasiinternet2016.pdf. Last accessed 10 October 2017.

Bressler, Hillary (2010). The Future of Mobile and Destination Marketing. www.slideshare.net/hillarybressler/future-of-mobile-fordestinationmarketing-and-travel. Last accessed 10 October 2017.

Davis, F. D. (1989). Perceived Usefulness, Perceived Ease of Use, and User Acceptance of Information Technology. MIS quarterly, Vol. 13 No. 3. pp. 319340 .

Im, Jin Young dan Hancer, M. (2014). Shaping Travelers' Attitude Toward Travel Mobile Applications. Journal of Hospitality and Tourism Technology, Vol. 5 Issue: 2. pp.177-193. 
Izza, Jamalul (2016). Internet Users in Indonesia Reach 132.7 Millions. http://tekno.kompas.com/read/2016/10/24/15064727/2016.pengguna.inter net.di.indo $\backslash$. Last accessed 10 October 2017.

Janga, Alderbetus U., Darsono, Junianto T., dan Respati, Harianto (2017). Pusat Informasi Pariwisata Kabupaten Sumba Tengah Berbasis Website. Jurnal Pariwisata Pesona, Vol. 2 No. 01 Juni 2017. pp. 1-11.

Morrison, Alastair M. (2010). Hospitality and Travel Marketing $4^{\text {th }}$ ed. Delmar Cengage Learning, Inc. United States.

O’Neill, J. dan Mattila, A. (2010). Hotel Brand Strategy. Cornell Hospitality Quarterly, Vol. 51 No. 1. pp.27-34.

Oulasvirta, A., Rattenbury, T., Ma, L. dan Raita, A. (2012). Habits Make Smartphone Use More Pervasive. Personal and Ubiquitos Computing, Vol.16 No.1. pp. 105114.

Rosidah dan Herawati (2013). Pola Komunikasi Mahasiswa Dalam Penggunaan Smartphone. Humaniora, Vol.4 No.2. pp. 883-893.

Sarjono, Haryadi dan Winda Julianita (2011). SPSS vs LISREL: Sebuah Pengantar, Aplikasi Untuk Riset. Jakarta: Salemba Empat.

Sekaran, Uma dan Bougie, Roger (2013). Research Methods for Business: A SkillBuilding Approach $6^{\text {th }}$ ed. John Wiley \& Sons Ltd. United Kingdom

Setiko, Rio K. R. dan Sani, Fitria E. A. (2016). Peranan Akurasi Sistem Komputer Hotel di Front Office Department Dalam Meningkatkan Kepuasan Tamu di The Balava Hotel Malang. Jurnal Pariwisata Pesona, Vol. 1 No. 02 Desember 2016. pp. 22-38.

Supranto. (2012). Metode Riset: Aplikasinya Dalam Pemasaran. Jakarta: Rineka Cipta.

Travelport (2017). Travelport Global Survey Highlights Different Digital Traveler Habits. https://www.travelport.com/company/mediacenter/pressreleases/2017-11-08/travelport-global-survey-highlightsdifferent-digital. Last accessed 10 October 2017.

United Nation of World Tourism Organization (2016). Sustained Growth in International Tourism Despite Challenges. http://cf.cdn.unwto.org/sites/all/files/pdf/unwto_barom17_01_january_ex cerpt_.pdf. Last accessed 10 October 2017. 